\title{
Стратегирование процессов развития научно-инновационной сферы субъектов Российской Федерации
}

\author{
И. E. Рисuн ${ }^{1 \bowtie}$ \\ ${ }^{1}$ Воронежский государственный университет, Университетская пл, 1, \\ 394018, Воронеж, Российская Федерация
}

Для цитирования: Рисин И. Е. Стратегирование процессов развития научно-инновационной сферы субъектов Российской Федерации // Вестник Воронежского государственного университета. Серия: Экономика и управление. 2020. № 3. C. 78-88. DOI: 10.17308/econ.2020.3/3107

Предмет. Стратегирование (стратегическое планирование) процессов развития научно-инновационной сферы субъектов Российской Федерации.

Цель. Оценка современной практики стратегического планирования процессов развития научно-инновационной сферы субъектов Российской Федерации (регионов), выявление присущих ей позитивных моментов и ограничений.

Методология. Использован метод контент-анализа стратегий социально-экономического развития регионов, дополненный методом сравнительного анализа представленных в них ключевых задач развития научно-инновационной сферы и мер, которые органы публичной власти намерены реализовать. Информационная база анализа включает разработанные в соответствии с требованиями Федерального закона Российской Федерации от 28 июня 2014 г. № 172 «О стратегическом планировании в Российской Федерации» актуализированные стратегии социально-экономического развития Воронежской, Московской, Нижегородской, Самарской областей, Санкт-Петербурга, Республики Татарстан, Хабаровского края.

Результаты и их обсуждение. К позитивным моментам практики стратегирования отнесена постановка задач, связанных с развитием рынка объектов интеллектуальной собственности, венчурного финансирования, международной производственной кооперации предприятий, экспорта инновационной продукции. Другой позитивный момент - разработка мер, являющихся сравнительно новыми для большинства регионов. В их числе меры, обеспечивающие создание центров поддержки технологий и инноваций на базе высших учебных заведений, формирование ведущих научных центров, в том числе мирового уровня; продвижение инновационных разработок представителей малого и среднего бизнеса на внешние рынки; закрепление в науке и инновационных видах деятельности молодых специалистов; решение социальных, жилищных и профессиональных проблем молодых ученых и перспективных исследователей; создание среды для онлайновых коммуникаций между разработчиками инноваций, бизнесом и государственными органами; пропаганда инновационной культуры через средства массовой информации и интернет; реализация информационной политики, направленной на повышение престижности инновационной и научной деятельности. В числе ограничений практики стратегирования определены осуществленная только в единичных стратегиях постановка новых задач развития научно-инновационной сферы; избирательность предложенных мер относительно состава поставленных ключевых задач.

Выводы. Выявленные позитивные моменты и ограничения современной практики стратегирования научно-инновационной сферы свидетельствуют о необходимости учета опыта продвинутых регионов, востребованного для обоснованного формирования необходимого состава ключевых задач ее развития и мер, обеспечивающих их эффективное решение.

Ключевые слова: стратегии регионов, задачи инновационного развития.

\section{Введение}

Актуальность темы исследования определяется необходимостью перехода экономики субъектов Российской Федерации на инновационный путь развития. Ключевым условием его осуществления является повышение отдачи от деятельности научно-инновационной сферы, обеспечивающей разработку, апробацию и внедрение технологических, продуктовых и организационных инноваций. Вместе с тем следует 
констатировать, что полученные в этой сфере результаты до сих пор далеки от ожидаемых. В числе причин такого положения - неразвитость теоретических представлений о ключевых задачах развития научно-инновационной сферы и необходимых мерах, посредством которых органы публичной власти могут обеспечить их эффективное решение.

Потребность в преодолении отставания теории от запросов практики активизировала научные исследования в названной предметной области. В работах отечественных ученых, в том числе представителей Воронежской школы управления, рассматривается широкий спектр проблем инновационного развития экономики Российской Федерации, ее регионов.

С позиций заявленной в данной статье научной задачи особого внимания заслуживают результаты исследований, полученные О. Г. Голиченко, идентифицировавшего и содержательно охарактеризовавшего основные факторы развития национальной инновационной системы [2], Л. А. Горюновой, раскрывшей структуру механизма управления инновационной системой региона [3], 3. Н. Мамаевой, предложившей методический подход к оценке инновационного развития регионов [8], С. В. Макар, выявившей пространственные закономерности развития инновационной деятельности в регионах России [7], Д. Ю. Трещевским, обосновавшим принципы и выбор необходимого инструментария управления инновационным развитием регионов [14], Л. М. Никитиной, А. Ю. Кособуцкой, И. Е. Рисиным, Е. Ф. Сысоевой, Ю.И. Трещевским, М. Б. Табачниковой, Г.Н. Франовской, оценившими угрозы и возможности инновационного развития экономики регионов [10;14; 18; 19; 20], Д. А. Ендовицким, М. Б. Табачниковой, Ю. И. Трещевским, включившими в предметное поле исследования институциональные аспекты стратегического управления развитием инновационной сферы регионов [17], Е. В. Ендовицкой, И. Е. Рисиным, Ю.И. Трещевским, обосновавшими постановку стратегических целей регионального развития и определивших его ограничения [16], а также исследований, посвященных проблемам технологизации региональной экономики (см. например, 3. В. Аутлева, В.Ш. Расумов [1], В. М.Джуха, К. Н. Мищенко [4], С. В. Кузнецов [6], К. Н. Мищенко, А. Н. Елецкий [9], О. А. Романова [11], П. В. Сергеев и др. [12], О. С. Сухарев [13] и др., О. С. Шварцман [15]). Однако потенциал стратегического планирования инновационных преобразований в экономике субъектов Рос- сийской Федерации исследован и реализован далеко не в полной мере.

В соответствии с требованиями Федерального закона Российской Федерации от 28 июня 2014 г. № 172 «О стратегическом планировании в Российской Федерации» субъекты Российской Федерации осуществили разработку актуализированных стратегий социально-экономического развития, один из разделов которых посвящен развитию научно-инновационной сферы регионов. В связи с этим оправданы постановка цели исследования, ориентированного на выявление общего и особенного в составах стоящих перед органами государственной власти субъектов Российской Федерации ключевых задач научно-инновационной сферы и мер, востребованных для их эффективного решения, получение оценки современной практики стратегического планирования процессов ее развития, выявление присущих ей позитивных моментов и ограничений.

Информационная база проведенного анализа представлена актуализированными стратегиями социально-экономического развития Воронежской ${ }^{1}$, Московской ${ }^{2}$, Нижегородской ${ }^{3}$, Самарской ${ }^{4}$ областей, Санкт-Петербурга ${ }^{5}, \mathrm{Pe}-$ спублики Татарстан ${ }^{6}$, Хабаровского края ${ }^{7}$

${ }^{1}$ О Стратегии социально-экономического развития Воронежской области на период до 2035 года: закон Воронежской области от 20.12.2018 №168-O3. URL: http://docs. cntd.ru/document/550300779 (дата обращения: 10.03.2020).

${ }^{2}$ О стратегии социально-экономического развития Московской области на период до 2030 года: постановление Правительства Московской области от 28.12.2018 №1023/45. URL: http // mef.vjsreg.ru/download/document/ 3526908 (дата обращения: 15.03.2020).

${ }^{3}$ О стратегии социально-экономического развития Нижегородской области до 2035 года. URL: http://strategy. goverment-nnov.ru (дата обращения: 15.03.2020).

${ }^{4}$ О Стратегии социально-экономического развития Самарской области на период до 2030 года: постановление Правительства Самарской области от 12.07.2017 №441. URL: http://docs.cntd.ru/document/450278243 (дата обращения: 20.03.2020).

${ }^{5}$ О Стратегии социально-экономического развития Санкт-Петербурга на период до 2035 года: постановление Правительства Санкт-Петербурга от 26.06.2018 №521. URL: http // kzags.gov.spb.ru/media/upload/strategia_2035. pdf (дата обращения: 25.03.2020).

${ }^{6}$ Об утверждении Стратегии социально-экономического развития Республики Татарстан до 2030 года: закон Республики Татарстан от 17.06.2015 №40-3PT. URL: http:// docs2.cntd.ru/document/428570021 (дата обращения: 25.03.2020).

${ }^{7}$ О стратегии социально-экономического развития Хабаровского края на период до 2030 года: постановление Правительства Хабаровского край от 13.06.2018 №215-пр. URL: http//docs.cntd.ru/document/465353006 (дата обращения: 25.03.2020). 


\section{Методы исследования}

Для решения поставленной научной задачи реализован авторский подход, предусматривающий:

- контент-анализ актуализированных стратегий социально-экономического развития российских регионов, позволяющий выявить ключевые задачи развития научно-инновационной сферы и меры, предложенные разработчиками для их решения;

- сравнительный анализ, результатом которого являются определение инвариантного (общего для регионов, оказавшихся в выборке) и особенного в составах задач и мерах, выявление позитивных моментов и ограничений современной практики стратегирования процессов развития научно-инновационной сферы регионов;

- включение в объектную базу анализа субъектов Российской Федерации, относящихся к разным федеральным округам.

\section{Обсуждение результатов}

Контент-анализ стратегий вышеназванных субъектов Российской Федерации позволил зафиксировать следующий состав ключевых задач развития научно-инновационной сферы.

Т а бли ц а 1

Ключевые задачи развития научно-инновационной сферы

в стратегиях социально-экономического развития субъектов РФ

\begin{tabular}{|c|c|}
\hline Субъекты РФ & Ключевые задачи развития научно-инновационной сферы \\
\hline $\begin{array}{l}\text { Воронежская } \\
\text { область }\end{array}$ & $\begin{array}{l}\text { Повышение эффективности взаимодействия бизнеса и сектора научно-исследователь- } \\
\text { ских разработок; формирование условий для развития рынка объектов интеллектуаль- } \\
\text { ной собственности; внедрение в деятельность органов государственного управления } \\
\text { современных инновационных технологий; обеспечение поддержки развития кадро- } \\
\text { вого потенциала инновационной деятельности; повышение уровня инновационной } \\
\text { культуры населения, восприимчивости бизнеса к инновациям }\end{array}$ \\
\hline & $\begin{array}{l}\text { транение инфраструктурных и институциональных ограничений расширения науч- } \\
\text { й и научно-производственной базы; развитие научно-технологических кластеров; } \\
\text { звитие особых экономических зон технико-внедренческого типа; расширение соста- } \\
\text { точек роста в сфере научно-технологической деятельности; формирование кадро- } \\
\text { й базы и кадрового резерва научной и научно-производственной сферы на уровне } \\
\text { чших мировых стандартов образования, теоретической и прикладной научных сфер }\end{array}$ \\
\hline $\begin{array}{l}\text { Нижегород- } \\
\text { ская область }\end{array}$ & $\begin{array}{l}\text { ормирование системы координации научно-технической деятельности; коммерциа- } \\
\text { пзация результатов научной деятельности; выведение инновационных продуктов на } \\
\text { ссийский и мировой рынки; развитие системы передачи результатов исследователь- } \\
\text { ой деятельности в реальный сектор экономики; развитие технологического предпри- } \\
\text { ммательства; развитие региональной системы финансирования инноваций; развитие } \\
\text { тфраструктуры для создания новых наукоемких производств; развитие экспорта инно- } \\
\text { ционной продукции }\end{array}$ \\
\hline $\begin{array}{l}\text { Самарская } \\
\text { область }\end{array}$ & $\begin{array}{l}\text { звитие университетской науки и фокусирование ее на приоритетных научных направ- } \\
\text { ниях; формирование региональной системы коммерциализации инноваций; развитие } \\
\text { лого инновационного бизнеса и создание рабочих мест в инновационных компаниях; } \\
\text { звитие и повышение эффективности механизмов поддержки инновационных компа-- } \\
\text { й; развитие детского и юношеского технического творчества }\end{array}$ \\
\hline $\begin{array}{l}\text { Санкт-Петер } \\
\text { бург }\end{array}$ & $\begin{array}{l}\text { звитие взаимодействия субъектов науки и образования, бизнеса и государства; развитие } \\
\text { укоемкого бизнеса; развитие международной производственной кооперации предпри- } \\
\text { ий; развитие системы подготовки и профессионального роста научных кадров; фор- } \\
\text { ирование эффективно работающего рынка продуктов и услуг в сфере интеллектуальной } \\
\text { бственности; продвижение продукции на региональных и международных рынках }\end{array}$ \\
\hline $\begin{array}{l}\text { Республика } \\
\text { Татарстан }\end{array}$ & $\begin{array}{l}\text { Формирование и развитие кадрового ресурса инновационной экономики; развитие } \\
\text { инновационно-инвестиционной инфраструктуры; развитие инновационной системы } \\
\text { через стимулирование развития формальных и неформальных внутренних институтов; } \\
\text { развитие рынка венчурных инвестиций; обеспечение конкурентоспособности и востребо- } \\
\text { ванности производимых инноваций на внутренних и внешних рынках (продукты, услуги, } \\
\text { технологии) }\end{array}$ \\
\hline $\begin{array}{l}\text { Хабаровский } \\
\text { край }\end{array}$ & $\begin{array}{l}\text { Усиление взаимосвязи подсистем и отдельных элементов внутри инновационной системы; } \\
\text { усиление взаимосвязи с подсистемами и элементами национальной инновационной систе- } \\
\text { мы; улучшение инновационной среды; формирование края как высокотехнологичного фор- } \\
\text { поста России в азиатско-тихоокеанском регионе; внедрение венчурного финансирования }\end{array}$ \\
\hline
\end{tabular}


Анализ данных табл. 1 свидетельствует о том, что в большинстве регионов, оказавшихся в нашей выборке, развитие научно-инновационной сферы связывается с повышением эффективности взаимодействия бизнеса, научных организаций и вузов в процессах разработки технологических и продуктовых новаций и их использования в реальной практике, формированием кадрового ресурса, адекватного требованиям инновационной экономики, развитием инновационной инфраструктуры.

Заметим, что названные задачи были поставлены в региональных стратегиях, предшествовавших нынешним, разработанным в первом десятилетии XXI века, однако, как свидетельствуют статистические данные, существенных позитивных результатов при их решении получить удалось далеко не везде. Так, доля инновационной продукции, работ и услуг в общем объеме отгруженных товаров, выполненных работ и услуг за период 2010-2018 гг. выросла в целом по Российской Федерации с 4,8 до 6,5 \% ${ }^{8}$ в Санкт-Петербурге - с 8,0 до 9,9\%, в Воронежской и Самарской областях иной тренд - снижение значения этого показателя с 7,1 до 5,9\%, с 14,2 до 13,5 \% соответственно.

Заметный рост в исследуемой выборке регионов получен только в Московской, Нижегородской области, Республике Татарстан и Хабаровском крае с 8,1 до 13,2 \%; 10,2 до 15,7 \%; 15,6 до 20,9 \%; 3,0 до 21,3 \% соответственно.

Не удалось и существенно нарастить долю организаций, осуществлявших технологические, маркетинговые и организационные инновации. Так, за период с 2010 по 2017 г. значения этого показателя выросли в Воронежской области с 8,6 до 11,7 \%, Московской области - с 6,7 до 8,9 \%, Санкт-Петербурге - с 13,0 до 16,1 \%, Республике Татарстан - с 15,6 до 20,9\%. В других субъектах Российской Федерации иной тренд - снижение: в Нижегородской области с 17,1 до $11,1 \%$, Самарской области - с 12,1 до 4,3 \%, Хабаровском крае - с 11,1 до 7,9 \%. Поэтому вполне логична постановка вышеприведенных задач и в актуализированных стратегиях.

Ожидаемо было появление новых задач, призванных сфокусировать внимание и действия субъектов научно-инновационной сферы в долгосрочной перспективе. Их постановка, однако, осуществлена только в единичных случаях, о чем свидетельствуют примеры целеполагания, связанные с развитием:

\footnotetext{
${ }^{8}$ Здесь и далее значения показателей получены на основе данных, представленных Федеральной службой государственной статистики.
}

а) рынка объектов интеллектуальной собственности (Воронежская область, Санкт-Петербург);

б) венчурного финансирования (Республика Татарстан, Хабаровский край);

в) детского и юношеского технического творчества (Самарская область);

г) международной производственной кооперации предприятий (Санкт-Петербург);

д) экспорта инновационной продукции (Нижегородская область, Санкт-Петербург, Республика Татарстан).

Полагаем необходимым особо отметить постановку задачи по развитию экспорта инновационной продукции, поскольку ее решение предполагает в первую очередь разработку и освоение принципиально новых технологий и продукции, не имеющих аналогов. В связи с этим укажем, что за последние годы заметного приращения и в этой области достичь не удалось. Так, доля принципиально новых технологий в общем числе разработанных в Российской Федерации передовых производственных технологий в 2010 г. составляла 13,4 \%, в 2017 г. - 15,7 \% [5]. Обратим также внимание на снижение значения этого показателя в производстве, обработке и сборке: в 2010 г. оно составляло 6,1 \%, в 2017 г. 5,6 \% [там же].

Контент-анализ стратегий позволил зафиксировать следующий состав мер, необходимых для развития научно-инновационной сферы названных субъектов РФ (табл. 2).

Анализ данных табл. 2 позволяет отнести к позитивным моментам практики стратегирования развития научно-инновационной сферы предусмотренные органами государственной власти меры по ее развитию, являющиеся сравнительно новыми для большинства субъектов Российской Федерации, например:

- создание центров поддержки технологий и инноваций на базе высших учебных заведений (Воронежская, Московская области, Санкт-Петербург);

- формирование ведущих научных центров, в том числе мирового уровня, инновационных научно-технологических центров (Московская, Нижегородская области, Санкт-Петербург);

- продвижение инновационных разработок представителей малого и среднего бизнеса на внешние рынки (Санкт-Петербург, Хабаровский край);

- открытие детских технопарков, центров молодежного инновационного творчества (Moсковская область); 
Меры органов государственной власти по развитию научно-инновационной сферы в стратегиях социально-экономического развития субъектов РФ

\begin{tabular}{|c|c|}
\hline Субъекты РФ & Меры органов власти по развитию научно-инновационной сферы \\
\hline 1 & 2 \\
\hline $\begin{array}{l}\text { Воронежская } \\
\text { область }\end{array}$ & $\begin{array}{l}\text { Содействие развитию технологических парков; создание центров поддержки техно- } \\
\text { логий и инноваций, в том числе на базе ведущих высших учебных заведений; реа- } \\
\text { лизация механизма государственно-частного партнерства в инновационной сфере; } \\
\text { стимулирование инновационной деятельности кластеров; государственная поддержка } \\
\text { системообразующих инновационных проектов; формирование системы государствен- } \\
\text { ной поддержки совместных проектов вузов и индустриальных партнеров по созданию } \\
\text { высокотехнологичных производств; поддержка малых инновационных предприятий; } \\
\text { предоставление субсидий из областного бюджета организациям, реализующим инве-- } \\
\text { стиционные проекты в инновационной сфере; привлечение и закрепление в науке и } \\
\text { инновационных видах деятельности молодых специалистов, введение системы индиви- } \\
\text { дуальных грантов для молодых ученых; создание среды для онлайновых коммуникаций } \\
\text { между разработчиками инноваций, бизнесом и государственными органами; пропаган- } \\
\text { да инновационной культуры через средства массовой информации и интернет }\end{array}$ \\
\hline $\begin{array}{l}\text { Московская } \\
\text { область }\end{array}$ & $\begin{array}{l}\text { Полное обновление приборной базы научных организаций, осуществляющих де- } \\
\text { ятельность в приоритетных направлениях развития научно-технической сферы; } \\
\text { участие в финансировании проекта «Создание не менее } 15 \text { научно-образовательных } \\
\text { центров мирового уровня на основе интеграции университетов и научных организа- } \\
\text { ций и их кооперации с организациями, действующими в реальном секторе экономи- } \\
\text { ки»; реализация мероприятий по созданию региональных объектов инновационной } \\
\text { инфраструктуры, таких как центры интеллектуальной собственности и трансфера } \\
\text { технологий; разработка соглашений о научно-техническом сотрудничестве на уровне } \\
\text { «регион - регион» с зарубежными административно-территориальными образовани- } \\
\text { ями - лидерами мирового хозяйства в научно-производственной сфере; создание си- } \\
\text { стемы передачи знаний и опыта молодым специалистам, имеющим свои инноваци- } \\
\text { онные разработки; решение социальных, жилищных и профессиональных проблем } \\
\text { молодых ученых и перспективных исследователей; привлечение внебюджетных ин- } \\
\text { вестиций в реализацию научных и научно-технических проектов; открытие детских } \\
\text { технопарков, центров молодежного инновационного творчества; предоставление } \\
\text { молодым ученым льготных условий ипотечного кредитования (социальная ипотека) }\end{array}$ \\
\hline & $\begin{array}{l}\text { Формирование лидирующих исследовательских центров в рамках национального про- } \\
\text { екта в сфере цифровой экономики, ведущих научных центров, в том числе мирового } \\
\text { уровня, научно-образовательных центров; поддержка молодых ученых и инноваторов, } \\
\text { работающих по приоритетным направлениям исследований; создание условий для } \\
\text { формирования в стране нового высокотехнологичного сектора промышленности по } \\
\text { производству инновационного продукта в биофотонике; создание ведущего лазерно- } \\
\text { го центра в мире; ориентация государственных заказчиков на закупку наукоемкой и } \\
\text { инновационной продукции, созданной на основе российских технологий; содействие } \\
\text { развитию частных фондов инвестиций; развитие системы предоставления налоговых } \\
\text { льгот для создания производств инновационной продукции; создание имиджа обла- } \\
\text { сти как ведущего центра в сфере науки и инноваций по приоритетным технологиям; } \\
\text { реализация информационной политики, направленной на повышение престижности } \\
\text { инновационной и научной деятельности }\end{array}$ \\
\hline $\begin{array}{l}\text { Самарская } \\
\text { область }\end{array}$ & $\begin{array}{l}\text { Создание финансовых и нефинансовых инструментов поддержки технологического } \\
\text { предпринимательства, осуществляемого в приоритетных отраслевых направлениях; } \\
\text { вовлечение регионального, федерального и международного частного венчурного } \\
\text { капитала в развитие технологического предпринимательства; содействие выходу } \\
\text { российских инновационных и сервисных бизнесов на глобальный рынок и их инте- } \\
\text { грации в международные цепочки создания стоимости; стимулирование инноваци- } \\
\text { онной активности компаний; содействие развитию детского и юношеского техниче- } \\
\text { ского творчества; популяризация инновационной деятельности }\end{array}$ \\
\hline
\end{tabular}


О кончание табл. 2

\begin{tabular}{|c|c|}
\hline 1 & 2 \\
\hline $\begin{array}{l}\text { Санкт-Петер- } \\
\text { бург }\end{array}$ & $\begin{array}{l}\text { Содействие созданию научных и научно-образовательных центров мирового уров- } \\
\text { ня на основе интеграции вузов и научных организаций и их кооперации с реальным } \\
\text { сектором экономики; создание условий для открытия представительств инжинирин- } \\
\text { говых компаний; открытие специализированных технопарков с акселерационной } \\
\text { программой и производственными центрами коллективного использования; развитие } \\
\text { инфраструктуры инновационно-промышленных парков, технологических парков, } \\
\text { особых экономических зон; обеспечение участия в реализации проектов Националь- } \\
\text { ной технологической инициативы; формирование новой технологической основы для } \\
\text { развития экономики и социальной сферы; привлечение представительств ведущих } \\
\text { мировых технологических брокеров; создание условий для открытия международных } \\
\text { исследовательских центров; стимулирование спроса на инновационную продукцию в } \\
\text { отраслях экономики; продвижение инновационной продукции и технологий на вну- } \\
\text { тренний и международные рынки; поддержка талантливых ученых и специалистов в } \\
\text { области научной, научно-технологической и инновационной деятельности; развитие } \\
\text { внешних академических связей с ведущими российскими и мировыми исследователь- } \\
\text { скими центрами; содействие формированию межвузовских научно-исследовательских } \\
\text { центров для создания и коммерциализации инновационных разработок; обеспечение } \\
\text { эффективного взаимодействия между исследователями, производителями, заказчика- } \\
\text { ми исследований, инвесторами и органами государственной власти; повышение каче-- } \\
\text { ства трудовых ресурсов, организации подготовки высококвалифицированных кадров, } \\
\text { ориентированных на потребности инновационных отраслей экономики }\end{array}$ \\
\hline & $\begin{array}{l}\text { Привлечение, подготовка, совершенствование и удержание кадров для инновацион- } \\
\text { ной системы; предоставление инновационным фирмам благоприятных условий для } \\
\text { ведения бизнеса, стимулирование их межфирменного взаимодействия в технопарках, } \\
\text { кластерах, технополисах; создание и поддержание комплексной инфраструктуры, обе- } \\
\text { спечивающей высокое качество жизни для работающих в регионе специалистов, а так- } \\
\text { же условий для ускоренного создания и внедрения инноваций; обеспечение активног } \\
\text { взаимодействия с внешними рынками товаров, услуг, технологий, капитала и кадров; } \\
\text { содействие в поддержке экспорта инновационных компаний и развитии международ- } \\
\text { ных межфирменных контактов; обеспечение конкурентоспособности и востребован- } \\
\text { ности производимых инноваций на внутренних и внешних рынках (продукты, услуги, } \\
\text { технологии) по приоритетным отраслям/кластерам; популяризация логики иннова- } \\
\text { ционного развития с описанием конкретных выгод с точки зрения каждого жителя; } \\
\text { формирование и обеспечение соблюдения прозрачных правил игры, известных и по- } \\
\text { нятных всем участниками инновационного процесса; формирование Института инно- } \\
\text { вационного развития Республики Татарстан; повышение уровня толерантности к риску } \\
\text { и неудачам - ключевым факторам устойчивого инновационного развития; формирова- } \\
\text { ние системы финансирования на всех стадиях инновационного процесса с преоблада-- } \\
\text { нием частных вложений, с особой концентрацией на привлечении «умных» денег }\end{array}$ \\
\hline $\begin{array}{l}\text { Хабаровский } \\
\text { край }\end{array}$ & $\begin{array}{l}\text { Стимулирование внутреннего инновационного спроса и максимальное использова- } \\
\text { ние спроса на национальном и китайском рынках; создание центров компетенций и } \\
\text { принятия решений по развитию технологий на предприятиях; стимулирование модер- } \\
\text { низации высоко- и среднетехнологичных отраслей, ориентированных в том числе на } \\
\text { глобальные рынки; создание сети технопарков как центров социальной, деловой и ин- } \\
\text { новационной инфраструктуры, трансфера и коммерциализации разработок, развития } \\
\text { малого и среднего высокотехнологичного бизнеса, хабом для построения региональ- } \\
\text { ной инновационной экосистемы, стимулирующим рост деловой активности и местом } \\
\text { создания новых рабочих мест; формирование кооперации с компаниями из стран } \\
\text { азиатско-тихоокеанского региона по внедрению передовых зарубежных технологий; } \\
\text { продвижение инновационных разработок представителей малого и среднего бизнеса } \\
\text { на внешние рынки; создание и удержание критической массы творческих людей - } \\
\text { специалистов, обладающи способностью участвовать в глобальных коммуникациях, } \\
\text { умением превращать знания в ценность для потребителей на международном рынке; } \\
\text { сохранение конкурентоспособных научных коллективов и отдельных ученых, способ- } \\
\text { ных внести вклад в решение реальных задач технологического развития }\end{array}$ \\
\hline
\end{tabular}


- закрепление в науке и инновационных видах деятельности молодых специалистов (Воронежская область), поддержка талантливых ученых и специалистов в области научной, научно-технологической и инновационной деятельности (Санкт-Петербург), решение социальных, жилищных и профессиональных проблем молодых ученых и перспективных исследователей (Московская область); удержание критической массы творческих людей специалистов, обладающих способностью участвовать в глобальных коммуникациях, умением превращать знания в ценность для потребителей на международном рынке (Хабаровский край);

- создание среды для онлайновых коммуникаций между разработчиками инноваций, бизнесом и государственными органами (Воронежская область), обеспечение эффективного взаимодействия между исследователями, производителями, заказчиками исследований, инвесторами и органами государственной власти (Санкт-Петербург);

- пропаганда инновационной культуры через средства массовой информации и интернет (Воронежская область), популяризация инновационной деятельности (Самарская область), реализация информационной политики, направленной на повышение престижности инновационной и научной деятельности (Нижегородская область), повышение уровня толерантности к риску и неудачам ключевым факторам устойчивого инновационного развития (Республика Татарстан).

Информация, представленная в табл. 2, позволяет зафиксировать и ограничения, присущие современной практике стратегирования процессов развития научно-инновационной сферы субъектов Российской Федерации. Главное из них - избирательность предложенных разработчиками актуализированных стратегий мер относительно состава поставленных ключевых задач.

В подтверждение этого вывода обратим внимание на отсутствие в стратегиях необходимых и достаточных мер, призванных обеспечить решение таких задач, как формирование в регионах рынка объектов интеллектуальной собственности, становление и развитие венчурного финансирования, создание международной производственной кооперации предприятий, развитие экспорта инновационной продукции и технологий.

\section{Заключение}

Контент-анализ актуализированных стратегий социально-экономического развития субъектов Российской Федерации, дополненный сравнительным анализом содержащихся в них ключевых задач развития научно-инновационной сферы и мер, призванных обеспечить их решение, позволяет сделать ряд выводов.

1. Учитывая выявленные позитивные моменты современной практики стратегического планирования, целесообразно расширять инвариантный (общий для российских регионов) состав ключевых задач развития научно-инновационной сферы.

Полагаем, что его обновленная версия должна включать следующие задачи: формирование и развитие инновационных кластеров; развитие малого инновационного бизнеса; обеспечение инновационного характера деятельности технологических и промышленных парков; развитие технологического предпринимательства; развитие взаимодействия субъектов науки и образования, бизнеса и государства; развитие инфраструктуры для создания новых наукоемких производств; развитие системы финансирования инноваций, включая венчурное финансирование; формирование необходимых условия для развития рынка объектов интеллектуальной собственности; развитие международной производственной кооперации предприятий; развитие экспорта инновационной продукции; обеспечение поддержки развития кадрового потенциала инновационной деятельности; развитие детского и юношеского технического творчества; повышение уровня инновационной культуры населения.

2. Учитывая опыт регионов, продвинутых в области стратегического планирования, целесообразно расширять инвариантный состав мер, призванных обеспечить эффективное решение ключевых задач развития научно-инновационной сферы. Полагаем, что его обновленная версия должна включать следующие меры: создание центров поддержки технологий и инноваций, в том числе на базе ведущих высших учебных заведений; открытие специализированных технопарков с акселерационной программой и производственными центрами коллективного использования; обеспечение участия в реализации проектов Национальной технологической инициативы; расширение практики реализации 
проектов государственно-частного партнерства в инновационной сфере; предоставление государственной финансовой поддержки малым инновационным предприятиям, инновационным кластерам, совместным проектам вузов и индустриальных партнеров по созданию высокотехнологичных производств; предоставление субсидий из регионального бюджета организациям, реализующим инвестиционные проекты в инновационной сфере; ориентация государственных заказчиков на закупку наукоемкой и инновационной продукции, созданной на основе российских технологий; содействие развитию частных фондов инвестиций; продвижение инновационных разработок бизнеса на внешние рынки; открытие (расширение сети) детских технопарков, центров молодежного инновационного творчества; введение системы индивидуальных грантов для молодых ученых и перспективных специалистов, предоставление им льготных условий ипотечного кредитования; создание среды для онлайновых коммуникаций между разработчиками инноваций, бизнесом и государственными органами; реализация информационной политики, направленной на повышение престижности инновационной и научной деятельности.

\section{Библиографический список}

1. Аутлева 3. В., Расумов В. Ш. Некоторые особенности формирования инновационной системы регионального хозяйственного комплекса // Вестник Академии знаний. 2020. № 3 (38). C. 49-52.

2. Голиченко О. Г. Основные факторы развития национальной инновационной системы: уроки для России. М. : Наука, 2011. 634 с.

3. Горюнова Л. А. Управление инновационной системой региона. Инструменты и механизм управления. СПб. : Изд-во СПБГУЭФ, 2001. 216 с.

4. Джуха В. М., Мищенко К. Н. Вопросы технологизации региональной экономики // Journal of New Economy. 2019. T. 20, № 3. C. 38-50.

5. Индикаторы науки: 2019 : статистический сборник / Л. М. Гохберг, К. А. Дитковский, Е. Л. Дьяченко и др. ; Нац. исслед. ин-т «Высшая школа экономики». М. : НИУ ВШЭ, 2019. С. 242.

6. Кузнецов С. В. Вопросы территориальной конкурентоспособности // Экономика и управление. 2015. № 6 (116). С. 84-85.

7. Макар С. В., Носов А. М. Оценка и пространственные закономерности развития инновационной деятельности в регионах России // Экономика регионов. 2017. № 4. С. 96-100.
3. Востребованными направлениями дальнейших исследований в этой области, по нашему мнению, могут стать:

- разработка условий и алгоритмов реализации инвариантного пакета мер, учитывающих интересы акторов инновационной системы - бизнеса, вузов и НИИ, государства;

- проведение бенчмаркинга, ориентированного на выявление эффективных практик государственной поддержки инновационной деятельности в зарубежных странах, разработка вариантов их эффективной адаптации к российским условиям;

- обоснование необходимых изменений в механизме управления развитием научно-инновационной деятельности в регионах с учетом постановки новых задач и обновлением состав мер, обеспечивающих их решение.

\section{Источник финансирования проведенного исследования}

Воронежский государственный университет.

\section{Конфликт интересов}

Автор декларирует отсутствие явных и потенциальных конфликтов интересов, связанных с публикацией настоящей статьи.

8. Мамаева 3. Н. Оценка инновационного развития регионов: эконометрический подход // Вестник Нижегородского государственного университета. 2012. № 2. С. 202-208.

9. Мищенко К. Н., Елецкий А. Н. Анализ потенциала и перспектив инновационного развития региона в условиях глобализации мировой экономики (на примере Ростовской области) // Региональная экономика: теория и практика. 2018. Т. 16, № 12 (459). С. 2335-2348.

10. Рисин И.Е., Сысоева Е. Ф. Оценка современной практики стратегирования политики новой индустриализации в субъектах Российской Федерации // Регион: системы, экономика, управление. 2020. № 1. C. 16-22. Doi 10.22394/1997-4469-2020-48-1-16-22

11. Романова О.А. Приоритеты промышленной политики России в контексте вызовов четвертой промышленной революции. Ч. 1 // Экономика региона. 2018. Т. 14, вып. 2. С. 420-432.

12. Сергеев П. В., Колмыкова Т. С., Сергеев В. П. О проблемах и основных условиях инновационного роста экономики регионов // Вестник Курской государственной сельскохозяйственной академии. 2019. № 3. С. 138-145.

13. Сухарев О. С. «Экономика технологий»: типы, функции, конкурентоспособность // Эконо- 
мическая наука современной России. - 2018. № 2. - С. 85-101.

14. Трещевский Д. Ю. Управление инновационным развитием регионов: принципы, стратегии, инструментарий. Воронеж : Издат.-полиграф. центр Воронеж. гос. ун-та, 2013. 176 с.

15. Швариман О. С. Проблемы и перспективы цифровизации системы государственных закупок России // Управление риском. 2020. № 1 (93). C. 56-64.

16. Endovitskaya E. V., Risin I. E., Treshchevsky Y.I. Strategic Goals of Socio-Economic Development of Regions in the Conditions of Economic and Financial Limitations // The Future of the Global Financial System: Downfall or Harmony. Lecture Notes in Networks and Systems / E. Popkova (Editor). Springer Nature Switzerland AG. (eBook). 2018. P. 229-235. URL: https://doi.org/10.1007/978-3-030-00102-5

17. Endovitsky D. A., Tabachnikova M. B., Treshchevsky Y. I. Analysis of the economic optimism of the institutional groups and socio-economic systems [Text] // ASERS. Journal of Advanced Research in Law and Economics. 2017. Vol. VII, iss. 6 (28). P. 1745-1752.

18. Risin I. E., Kanapukhin P. A., Sysoeva E. F., Petrykina I. N. / Assessing the Practical Strategizing of the Regional Policy on the Development of the Digital
Economy // Lecture Notes in Networks and Systems. Digital Economy: Complexity and Variety vs. Rationality. Vol. 87. 2020. Pp. 563-571. URL: https://doi. org/10.1007/978-3-030-29586-8.

19. Risin I.E., TreshchevskyY.I., Tabachnikova M. B., Franovskaya G. N. Public Authorities and Business on the Possibilities of Region's Development [Text] // In: Popkova E. (eds.) Overcoming Uncertainty of Institutional Environment as a Tool of Global Crisis Management. Contributions to Economics. Springer, Cham, 2017. №9783319606958. P. 55-62. DOI - https://doi. org/10.1007/978-3-319-60696-5_8

20. Risin I. E., Treshchevsky Yu. I., Nikitina L. M., Kosobutskaya A. Yu. / Analysis of Expert Assessments of Opportunities and Threats To Innovative Development of Regional Economies // Proceedings of the Russian Conference on Digital Economy and Knowledge Management [RuDEcK 2020]. ISSN of Advances in Economics, Business and Management Research is 2352-5428. Corresponding Author I.E. Risin Available Online 1 August 2020. P. 551-556. Indexation: CPCI (part of Clarivate's Web of Scence), CNKI, Wanfang Data and Google Scholar, Ei Compendex and Scopus. DOI https://doi.org/10.2991/aebmr.k.200730.101. URL: https://www.atlantispress.com/proceedings/ rudeck-20/125942683
Рисин Игорь Ефимович, доктор экономических наук, профессор, заведующий кафедрой региональной экономики и территориального управления Воронежского государственного университета, Воронеж, Российская Федерация

E-mail: risin@mail.ru

ORCID: 0000-0002-4472-1809
Поступила в редакцию 20.05.2020

Подписана в печать 10.09.2020 
UDC $33.011 ; 332.14$

DOI: $10.17308 /$ econ.2020.3/3107

JEL: B40; H10; R58

Licence: CC BY 4.0

\title{
Strategizing development processes research and innovation sphere of subjects Russian Federation
}

\author{
I. E. Risin ${ }^{1 凶}$ \\ ${ }^{1}$ Voronezh State University, 1, University sq., Voronezh, 394018, Russian Federation
}

Cite as: Risin, I. E. Strategizing development processes research and innovation sphere of subjects Russian Federation. Proceedings of Voronezh State University. Series: Economics and Management. 3, 78-88. (In Russ., abstract in Eng.). DOI: 10.17308/econ.2020.3/3107

Subject of research. Strategizing (strategic planning) of the development of the scientific and innovative sphere of the Russian Federation subjects.

The purpose of the study. The purpose of the study is to assess the current practice of strategic planning of the development of the scientific and innovative sphere of the Russian Federation (regions), to identify its inherent positive aspects and limitations.

Methodology. The method of content analysis of strategies for socio-economic development of regions was used, supplemented by a comparative analysis of the key tasks presented in them for the development of the scientific and innovative sphere and the measures that the public authorities intend to implement. The information base of the analysis includes updated strategies for social and economic development of the Voronezh, Moscow, Nizhny Novgorod, and Samara regions developed in accordance with the requirements of the Federal law of the Russian Federation No. 172 of June 28, 2014 «on strategic planning in the Russian Federation».

Results and discussion. The positive aspects of the strategy practice include setting tasks related to the development of the market for intellectual property objects, venture financing, international production cooperation of enterprises, and the export of innovative products. Another positive aspect is the development of measures that are relatively new for most regions. These include measures to ensure: the creation of technology and innovation support centers based on higher education institutions, the formation of leading research centers, including world-class ones; promotion of innovative developments of small and mediumsized businesses to foreign markets; consolidation of young specialists in science and innovative activities; solution of social, housing and professional problems of young scientists and prospective researchers; creation of an environment for online communications between innovation developers, business and government agencies; promotion of innovative culture through mass media and the Internet; implementation of information policy aimed at increasing the prestige of innovation and scientific activities. Among the limitations of the practice of strategizing is defined: carried out only in a few strategies, setting new targets for the development of scientific-innovative sphere; selectivity of the proposed measures concerning the composition of the key objectives identified.

Conclusions. Identified positive aspects and limitations of contemporary practice in strategies of scientificinnovation sphere indicate the need for learning from the experience of advanced regions, demand for policy formation necessary key tasks of its development and measures to ensure their effective solution.

Key words: strategies of regions, tasks of innovative development.

\section{Source of financing}

The source of funding for the research process is the Voronezh State University.

\section{References}

1. Outleva, Z. V. \& Rasumov, V. Sh. (2020) Some features of the formation of an innovation system regional economic complex. Vestnik Akademii Znaniy. 3 (38), 49-52. (In Russ.)

2. Golichenco, O. G. (2016) The main factors in the development of the national innovation system: lessons for Russia. Moscow, Nauka. (In Russ.)

\section{Conflict of Interest}

The author declares that there are no obvious or potential conflicts of indifference related to the publication of this article.

3. Gorunova, L. A. (2001) Managing the region's innovation system. Tools and control mechanism. Saint Petersburg, SPBGUEF publ. (In Russ.)

4. Dzhukha, V. M. \& Mishchenko, K. N. (2019) [The issues of regional economy technologisation]. Journal of new economy. 20 (3), 38-50. (In Russ.)

5. Gokhberg, L. M., Ditkovsky, K. A. \& Dyachenko E. L. et al. (2019) Indicators of science: 2019: statistical 
collection. Moscow, The Higher School of Economics Publ. (In Russ.)

6. Kuznetsov, S. V. (2015) Issues of territorial competitiveness. Economics and Management. 6(116), 84-85. (In Russ.)

7. Makar, C. V. \& Nosov,A.M. (2017) [Assessment and spatial patterns of innovation development in the regions of Russia]. Economics of regions. 4, 96-100. (In Russ.)

8. Mamaeva, Z. N. (2012) [Assessment of innovative development of regions: an econometric approach]. Bulletin of the Nizhny Novgorod state University. 2, 202208. (In Russ.)

9. Mishchenko, K. N. \& Eletskii, A. N. (2018) An analysis of the regional innovation development potential and prospects under the world economy globalization: some evidence from the Rostov oblast. Regional economics: theory and practice. 16 (12), 2335-2348. (In Russ.)

10. Risin, I. E. \& Sysoeva, E. F. (2020). [Evaluation of modern practice of strategizing the policy of new industrialization in the subjects of the Russian Federation]. Region: systems, economics, management. 1, 16-22. DOI: 10.22394/1997-4469-2020-48-1-16-22 (In Russ.)

11. Romanova, O. A. (2018) Industrial policy priorities of Russia in the context of challenges of the fourth industrial revolution. Part 1. Economy of Region. 14 (2), 420-432. (In Russ.)

12. Sergeev, P. V., Kolmykova, T. S. \& Sergeev, V. P. (2019) [On the problems and basic conditions of innovative growth of the economy of the regions]. Proceedings of Kursk State Agrarian Academy. 3, 138-145. (In Russ.)

13. Sukharev, O. S. (2018) "Economics of technologies”: types, functions, competitiveness. Economics of contemporary Russia. 2, 85-101. (In Russ.)

14. Treshevski, D. U. (2013) Management of innovative development of regions: principles, strategies, tools. Voronezh, Voronezh St. Univ. Publ. (In Russ.)
15. Shvartsman, O. S. (2020) [Problems and perspectives of digitalization of public procurement system]. Upravlenie Riskom. 1 (93), 56-64. (In Russ.)

16. Endovitskaya, E. V., Risin I. E. \& Treshchevsky Y. I. (2018) Strategic Goals of Socio-Economic Development of Regions in the Conditions of Economic and Financial Limitations. The Future of the Global Financial System: Downfall or Harmony. In E. Popkova (ed.) Lecture Notes in Networks and Systems. Springer Nature Switzerland AG. (eBook), 229-235. DOI: 10.1007/9783-030-00102-5

17. Endovitsky, D. A., Tabachnikova M. B. \& Treshchevsky Y.I. (2017) Analysis of the economic optimism of the institutional groups and socio-economic systems. ASERS. Journal of Advanced Research in Law and Economics. VII (6), 1745-1752.

18. Risin, I. E, Kanapukhin, P. A., Sysoeva, E. F. \& Petrykina, I. N. (2020) Assessing the Practical Strategizing of the Regional Policy on the Development of the Digital Economy. In Popkova, E. G. \& Sergi B. S. (eds.) Digital Economy: Complexity and Variety vs. Rationality, 563 - 571. DOI: 10.1007/978-3-030-29586-8.

19. Risin, I. E. Treshchevsky, Y.I. Tabachnikova, M. B. \& Franovskaya, G. N. (2017) Public Authorities and Business on the Possibilities of Region's Development In: Popkova E. (ed.) Overcoming Uncertainty of Institutional Environment as a Tool of Global Crisis Management. Contributions to Economics. Springer, Cham. P. 55-62 DOI: 10.1007/978-3-319-60696-5_8.

20. Risin, I. E., Treshchevsky, Yu. I., Sysoyeva, E. F., Nikitina, L. M. \& Kosobutskaya, A. Y. (2020). Analysis of Expert Assessments of Opportunities and Threats to Innovative Development of Regional Economies. In Proceedings of the Russian Conference on Digital Economy and Knowledge Management (RuDEcK 2020). DOI: $10.2991 /$ aebmr.k.200730.101
Igor E. Risin, Doctor of economics, Professor, Head of the Regional Economy and Territorial Development Chair at The Voronezh State University, Voronezh, Russian Federation

E-mail:risin@mail.ru

ORCID: 0000-0002-4472-1809
Received 20.05.2020

Accepted 10.09.2020 